\title{
Hernia intercostal abdominal inducida por tos
}

\author{
Cough-induced abdominal intercostal hernia
}

Lorena Arrabal-Agüera ${ }^{1}$, Fernando Jesus De Santiago-Urquijo ${ }^{2}$, Tamara Montoto-Fernández ${ }^{2}$ y Enrique Pedro Cormezana-Lizarribar ${ }^{2}$

Varón de 85 años que consulta por dolor y tumoración en flanco izquierdo (Figura 1). Como único antecedente cuenta tos desde hace 15 días y hematoma, sin traumatismo asociado. En TAC se objetiva una hernia intercostal en hipocondrio izquierdo que contiene colon, sin lesión diafragmática asociada (Figura 2).

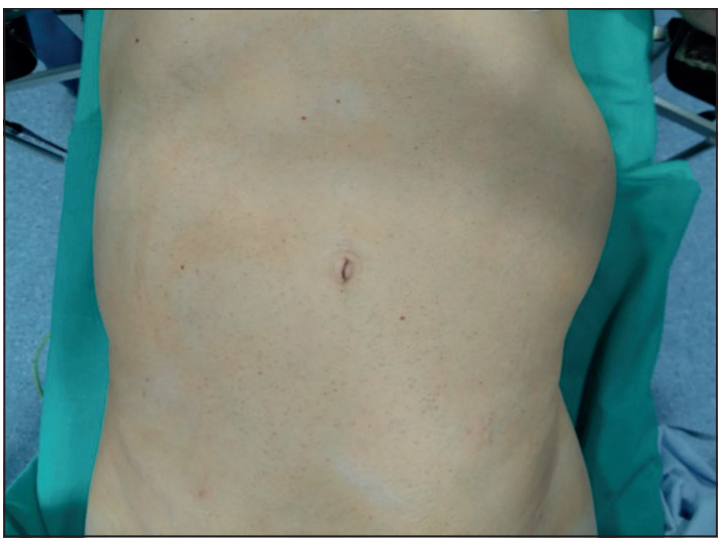

Figura 1. Aspecto externo de hernia, una vez en mesa de quirófano.

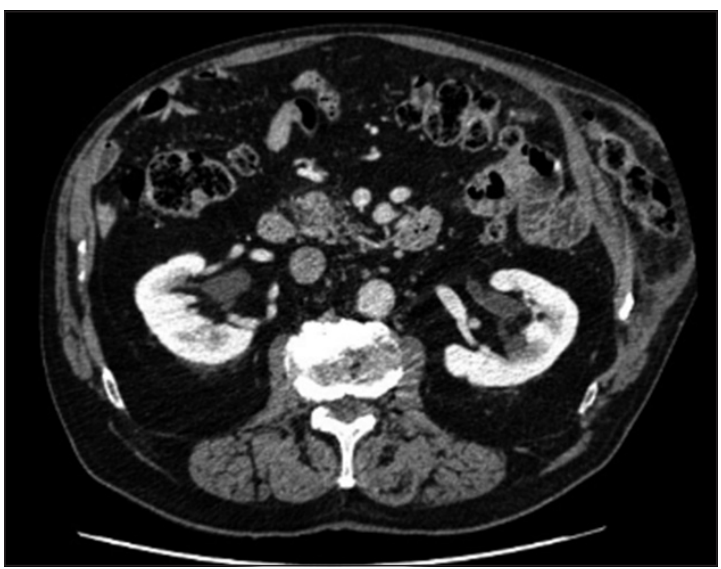

Figura 2. TC corte axial. Se objetiva hernia intercostal izquierda.
Por laparoscopia se observa un defecto de pared intercostal que contiene asas de intestino delgado y colon que se reduce (Figura 3). Se realiza incisión sobre el defecto herniario y plastia por vía anterior.

La hernia intercostal abdominal directa espontánea es una entidad muy poco frecuente. La mayoría de casos publicados corresponden a hernia intercostal pulmonar, o hernia abdominal transdiafragmáticas $^{1}$, ya que hay confusión en cuanto a la terminología. Hasta ahora solo hay 20 casos publicados ${ }^{2}$ de hernia intercostales abdominales directas, es decir, sin defecto asociado del diafragma. La mayoría de ella son secundarias a traumatismo, únicamente se han descrito 7 casos asociados a tos ${ }^{3}$.

No hay consenso sobre el tratamiento de elección. En general, se recomienda cirugía por las posibles complicaciones. Si el defecto es directo se recomienda toracotomía, si es indirecto laparoscopia o laparotomía. De elección: colocar malla sin tensión, y evitar alambres para disminuir el espacio entre las costillas ${ }^{1}$.

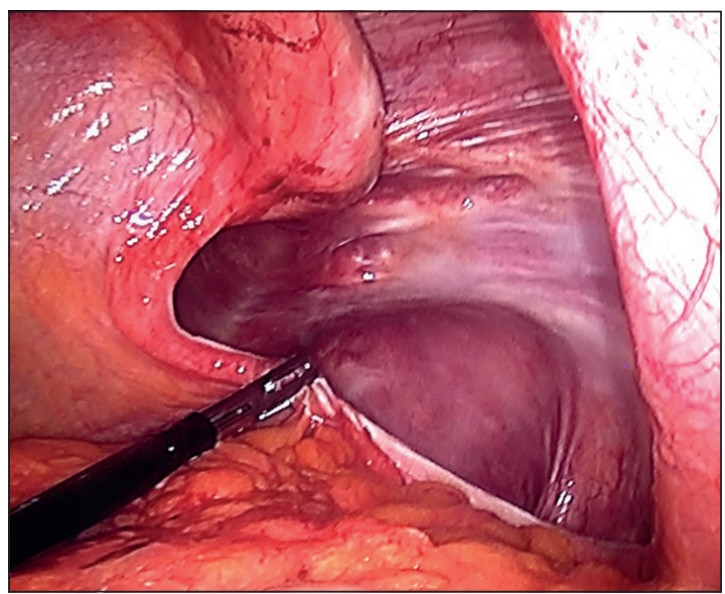

Figura 3. Imagen intraoperatoria.
Servicio de Cirugía General y del Aparato digestivo. Hospital Universitario Donostia. Donostia, San Sebastián. ${ }^{2}$ Servicio Cirugía General y del aparato Digestivo Hospital Bidasoa, Irun. Gipuzkoa, España.

Recibido 2020-10-27 y aceptado 2020-11-03

Correspondencia a:

Dra. Lorena Arrabal-Agüera lorenarrabal18@gmail.com 


\section{Responsabilidades éticas}

Protección de personas y animales. Los autores declaran que para esta investigación no se han realizado experimentos en seres humanos ni en animales.
Confidencialidad de los datos. Los autores declaran que en este artículo no aparecen datos de pacientes.

Conflictos de interés: no hay.

\section{Bibliografía}

1. Erdas E, Licheri S, Calo PG, Pomata M Acquired abdominal intercostal hernia: case report and systematic review of the literature. Hernia 2014;18:60715. doi:10.1007/s10029-014-1232-x. Epub 2014 Mar 13.

2. Abunnaja S, Chysna K, Shaifh I, Tripodi G. Acquired abdominal intercostal hernia: a case report and literature review. Case Rep Surg. 2014;456053. doi: 10.1155/2014/456053. Epub 2014 Aug 17.

3. Connery A, Mutvalli E. Couch-induced abdominal intercostal hernia. JRSM Short Rep. 2010;1:23. doi: 10.1258/ shorts.2010.010029. 